\title{
Papers
}

\section{Achieving a step change in contact centre performance: Exploiting data to make better decisions and take effective action}

Received (in revised form): 2nd June, 2003

\section{Peter Holland}

is Head of Customer Operations, Detica. Before joining Detica in 2001, Peter was European Director of CRM at Brann Worldwide. His core expertise is in operational CRM where he has specialised in the strategy, design, implementation and operational management of multichannel customer communication programmes. These typically involved contact centres (inbound and outbound telephony, mail, e-mail and fax communications) working in cooperation with one or more of the following operational areas: website, direct mail, field sales, fulfilment and data capture. He has experience in both business-to-business and business-to-consumer communication.

Peter Holland

Head of Customer Operations, Detica Ltd, Surrey Research Park, Guildford, Surrey GU2 7YP, UK.

Tel: +44 (0)1483 442000; Fax: +44 (0)1483 442280; e-mail: peter.holland@detica.com

\begin{abstract}
An examination of performance measurement and strategies for performance enhancement within contact centres, this paper reviews performance measures that have proven problematic and looks at the impact of measurement on employee motivation. The paper moves on to look at what contact centres should really be measuring - value delivered to the customer and value delivered to the business and how to publish results to the organisation, in order to catalyse action and change.
\end{abstract}

\section{INTRODUCTION}

Telephone, fax and e-mail have become established communications media, providing efficient and convenient means for customers and organisations to interact.

Since the 1980s, organisations have taken advantage of economies of scale by centralising the core handling of these media from previously separate and distributed marketing, sales and servicing operations. Initially termed call centres and predominantly telephone based, they have broadened into contact centres to include the handling of fax, e-mail and web-related communications. In this paper, the term contact centre is used to refer to both contact centres and call centres.

Centralising the contact centre functions has also provided the necessary control for companies to embark more effectively on a variety of strategies, such as reducing 'cost to serve' and differentiated customer service. Companies adopting a contact centre strategy early gained competitive advantage. For some, like First Direct, the contact centre was a key differentiator for their market proposition and essential to their brand positioning.

The contact centre strategy has now been widely adopted. The extent of this is indicated by research conducted by Datamonitor, showing that 1.2 per cent of the European workforce was employed in call centres in 2002. They forecast that this will rise to 1.6 per cent in $2007 .^{1}$

With contact centres now the norm, the playing field is once again level. Competitive advantage will belong to 
those whose contact centres deliver value to the shareholders, the customers and the employees. This paper argues that effective measurement of the correct value and efficiency indicators is the key to achieving this and outlines how this can be accomplished.

\section{WHAT GETS MEASURED GETS DONE}

Much of the change seen in contact centres has been technology led. Much has been written about the interplay between technology and business process in the context of return on investment (ROI). For example, did projects fail to deliver ROI because they simply implemented existing processes on new technology?

ROI means improving performance and the real questions are:

- how is performance defined?

- is it measured now?

- are these measures combined with additional management information to manage and improve business performance?

- how is appropriate measurement turned into appropriate action?

- can the improvements delivered be measured?

Measures of contact centre performance have been built up over the last 20 years and are now deeply embedded in business culture. The following are typical and show reported UK averages for 2001: ${ }^{2}$

- 68 per cent of calls answered in ten seconds;

- 23 seconds average time to answer;

- an average abandonment rate of 4.4 per cent;

- agents spending an average of 56 per cent of their time on call with a customer;
- an overall cost of $f^{0} 0.60$ per call minute.

It is interesting to note that, while each of these figures are individual averages, any contact centre operating consistently at all of these levels, with high rather than average customer satisfaction, would actually be among the top performing operations in the UK.

There is a problem with these types of metric. They focus primarily on the responsiveness of the contact centre to the demand for service and on some basics of efficiency. They:

- do not reflect the delivery of value to the customer and to the business;

- do not measure all of the activities of a contact centre;

— hide variations in performance.

The result is that they do not provide a good basis to support decisions to manage and improve contact centre performance. The following sections explore two typical symptoms.

\section{SYMPTOM 1: THE WATERBED EFFECT}

There are a variety of options for improving contact centre performance. Examples include:

- introduction and extension of self-service: to reduce call volumes;

- skills-based routing: to ensure the customer is connected to an appropriate agent;

— value-based routing: to provide differentiated levels of service;

- error reduction: to increase efficiency and service levels;

- multi-skilling staff: to increase their utilisation;

- dynamic workload allocation: to increase staff utilisation; 
- focusing on one call resolution: to reduce call-backs and service completion times.

The challenge, however, is what is sometimes referred to as 'the waterbed effect'. Just as the marketer focuses on one aspect and pushes down in one area, something pops up somewhere else. For example, an initiative to reduce call durations can end up reducing the percentage of issues resolved in a single call, thereby increasing the overall call demand on the contact centre and reducing customer satisfaction.

It is common to see contact centres undertaking a succession of isolated performance improvement initiatives without making long-term gains. The reason is often that there is an absence of a holistic set of suitable measures against which to judge the effectiveness of initiatives and then fine-tune them. This is becoming more of an issue, as the contact centre has to cater for the increasing complexity of products and an increasing number of:

- different communication media into a contact centre;

- marketing campaigns and promotions;

- complex interplays between media, product, promotion and marketing campaigns.

This diversification can make it difficult to remain focused on core issues. A contact centre trying to respond appropriately to e-mails generated through 'self-service' web sessions can create far greater load on itself than if the customers had just called.

\section{SYMPTOM 2: HEADS YOU LOSE, TAILS YOU LOSE}

Some have likened the achievement of a contact centre's objectives to the toss of a coin. Heads - they have understaffed, come in below cost, but delivered low levels of customer service.

Tails - they have delivered high levels of customer service, have overstaffed and overrun their costs.

Only if the coin lands on its edge will they have delivered to their objectives.

This view emphasises the complex balancing act that is required to optimise a contact centre's performance.

Delivering performance for the business is dependent upon the centre performing for both customers and employees. Contact centres, therefore, have three distinct groups of stakeholders: customers, employees and the business.

Each of these is now considered.

\section{WHAT CUSTOMERS REALLY, REALLY WANT}

The importance of service in terms of the customer proposition, and the importance of positioning in relation to the competition, is increasing. The level of importance will vary depending on the product being sold and supported. As customers, most people can identify good and bad service experiences and how this has affected their view of brands.

How fast the phone is answered is important to customers but it is far from the whole story. Research carried out by Detica $^{3}$ identified the three key factors by which customers value the experience they receive:

- facilitation: 'it needs to make my life easier';

- control: 'I need to feel that I am in the driving seat';

- relevance: 'it needs to make me feel like an individual and not just a number'.

As a comparison, the levels of satisfaction reported by consumers within the same 
research are pretty damning:

- only 29 per cent of consumers feel that their suppliers have made their lives easier;

- only 19 per cent feel in control;

- only 21 per cent say that their supplier makes them feel like an individual.

The factors that contribute directly to these customer value indicators include, for example:

- how many calls they had to make to resolve a single issue;

- how often an issue could be resolved by speaking to one person;

- how often they received contradictory information.

But these factors are rarely measured on a consistent basis. Even where customers are asked to provide feedback on how they were handled, it is generally in the context of the individual call that just took place. Rarely is a customer given the opportunity to explain that this call was fine - it was the four previous calls which they had to make to get to this point, which made them angry.

\section{PEOPLE ARE THE CENTRES' MOST IMPORTANT ASSET}

Research by Income Data Services ${ }^{4}$ puts employee churn as high as 30 per cent and shows contact centre wages rising at a higher rate than inflation. Employee dissatisfaction is a major cost to the business and dissatisfied employees do not generally foster satisfied customers. Each new recruit takes time to train and become sufficiently experienced to deliver the desired quality of service.

Meaningful measures are central to achieving effective team behaviour and improving employee satisfaction. Narrow measures that focus only, for example, on numbers of calls per hour or number of minutes to wrap up after each call can foster cynical behaviour and are generally counterproductive to providing good customer service.

Measures which focus on customer problem resolution, however, can be much more effective in fostering a highly collaborative approach to driving up performance.

\section{CONTACT CENTRE - SERVICE PROVIDER OR CUSTOMER CHAMPION?}

Meeting the needs of the customers and the employees is only a means to an end. Ultimately, the extent to which customers' and employees' needs are met by the contact centre should be directed by the business.

Brands differentiated by high levels of customer service will require that the contact centre act as a leader in the provision of high-quality service. Centre agents who can go the extra mile for the customer are critical to achieving this.

Conversely, brands differentiated on low cost will offer a cheaper, basic level of service to the customer. In these cases, the contact centre will be required only to provide the basics with longer queues and wait times being acceptable to the business. Although staff are still critically important, the valued behaviours will be those providing only the basics and no more.

For businesses to set the appropriate direction to the contact centre, it is necessary to understand the performance of the contact centre in terms of the value delivered to the enterprise. Contact centres are engaged in a range of services across the spectrum of business activities, including marketing, sales and service delivery. The performance of any one of 
Table 1: Unpicking contact centre activities by the value they deliver

\begin{tabular}{|c|c|c|}
\hline Customer value activities & Business value activities & Enabling activities \\
\hline $\begin{array}{l}\text { Deliver value directly to } \\
\text { customers and hence indirectly } \\
\text { to the business }\end{array}$ & $\begin{array}{l}\text { Deliver value directly to the } \\
\text { business }\end{array}$ & $\begin{array}{l}\text { Support the value activities and } \\
\text { drive contact centre efficiency }\end{array}$ \\
\hline Gain information about products & Launch new products & Recruitment \\
\hline Specify the product & Execute marketing campaigns & Training \\
\hline Obtain quotations & Cross-sell and up-sell & Personnel development \\
\hline Place an order & Promote new payment methods & Forecasting demand \\
\hline Pay & Migrate customers to self-service & Staff rostering \\
\hline Receive the product & & Workload management \\
\hline Obtain help on product use & & Fraud detection \\
\hline Resolve billing enquiries & & Fraud prevention \\
\hline Resolve issues & & Financial management \\
\hline
\end{tabular}

these functions and the business as a whole depend on an often complex interaction of process and activities, which sit both within the contact centre sphere of operation and outside it in other parts of the business.

The effectiveness of the interface between the contact centre and the rest of the business plays a substantial role in, for example, the speed with which new products can be taken to market or marketing campaigns launched. Too often, however, the processes and procedures to carry out these activities are not defined or measured by the businesses, let alone the contact centre operation.

This highlights an interesting question. Is the contact centre a supplier of services to the rest of the business, or the other way around? Traditionally, the former has been true and contact centre outsourcing reinforces that model.

In some businesses, the tide is moving in the other direction. Where they have signed up to a philosophy of being customercentric rather than productcentric, the next challenge is often how to embed that approach within the organisation. Contact centres have become the ears and voice of the brand. All too often agents take the brunt of poor service delivered to the customer from elsewhere in the organisation. The contact centre is, therefore, ideally positioned to be the owner of the customer in the operations of the business.

For performance to be improved, the type of role the centre plays - service provider or customer champion - and its relationship with the rest of the business, need to be clearly understood. Processes and activities need to be defined and meaningful measures representing the value they deliver to all three stakeholder groups, put in place.

\section{WHAT TO MEASURE?}

The key to understanding what should be measured is to unpick the activities of the contact centre from the perspective of value delivered to customers and value of the contact centre operation to the business. Table 1 illustrates how it is possible to identify and categorise contact centre activities.

\section{WHAT DATA AND INFORMATION ARE AVAILABLE TO MEASURE THESE ACTIVITIES?}

There are several information sources: customers, call centre agents, technology and applications supporting communications. The nature of the data and information is different from each source, as detailed below. 


\section{Getting information from the customer}

The customer is the key source for attitudinal information, obtained through qualitative and quantitative research methods. This is often used to measure customer satisfaction, but the problem is that results often do not give a clear guide on what action might be taken for improvement. To inform action, the research must produce results that clarify the different stages of the relationship between the customer and the business. In this way, agent responsiveness can be more tailored to specific needs - from a customer looking for initial information with a view to purchase, to a regular customer who may also act as an advocate for the brand when talking to friends.

\section{Gathering information from the contact centre agents}

Agents are the only people in the contact centre who have personal experience of interactions with customers. Their gut feel and anecdotal information can be invaluable. A key role of the agent is to record information on the customer interaction where possible, by entering data into computer systems. This function is critical to ensuring that any secondary activity required to resolve customer enquiries can be successfully carried out, making consistent and accurate data available to support future interactions. This is a valuable source of information, forming the basis of performance monitoring and measurement.

\section{Gathering information from the technology and supporting applications}

The variety of contact centre technologies and supporting applications, which are essential to support customer interactions, are a prime source of data on customer behaviour. These data are contained in a variety of databases, contact management and back office systems.

Importantly, the data contained in call recording applications should not be overlooked. This is rich information which can now be mined using voice to text, tonal and voice recognition technologies. These enable the recording base to be searched for key words and to identify calls from the same customer.

\section{Data on each individual interaction}

For each customer interaction, the data spread across the contact centre systems will contain the time of contact, length of wait, whether they abandoned, agent handler and length of interaction. At this point, centres vary in the depth of data held. Some have integrated contact management systems recording all key activities. Others will use back office systems for details of orders placed, information despatched, billing records accessed.

The variable quality of these data is confirmed by results from a research programme carried out into organisations' capabilities to convert data into decisions. ${ }^{5}$ Figure 1 shows how companies rated the quality of different types of data that they had stored.

Although the systems may not be integrated, the logs and data that they contain can be brought together in a single repository. It is often not possible for all of the records to be matched in a way that can show details of all interactions. To draw out useful findings, however, it is necessary only to hold data on a representative sample of the interactions.

\section{Tying together multiple interactions for the same customer}

Understanding the complete interaction history of a customer is obviously 


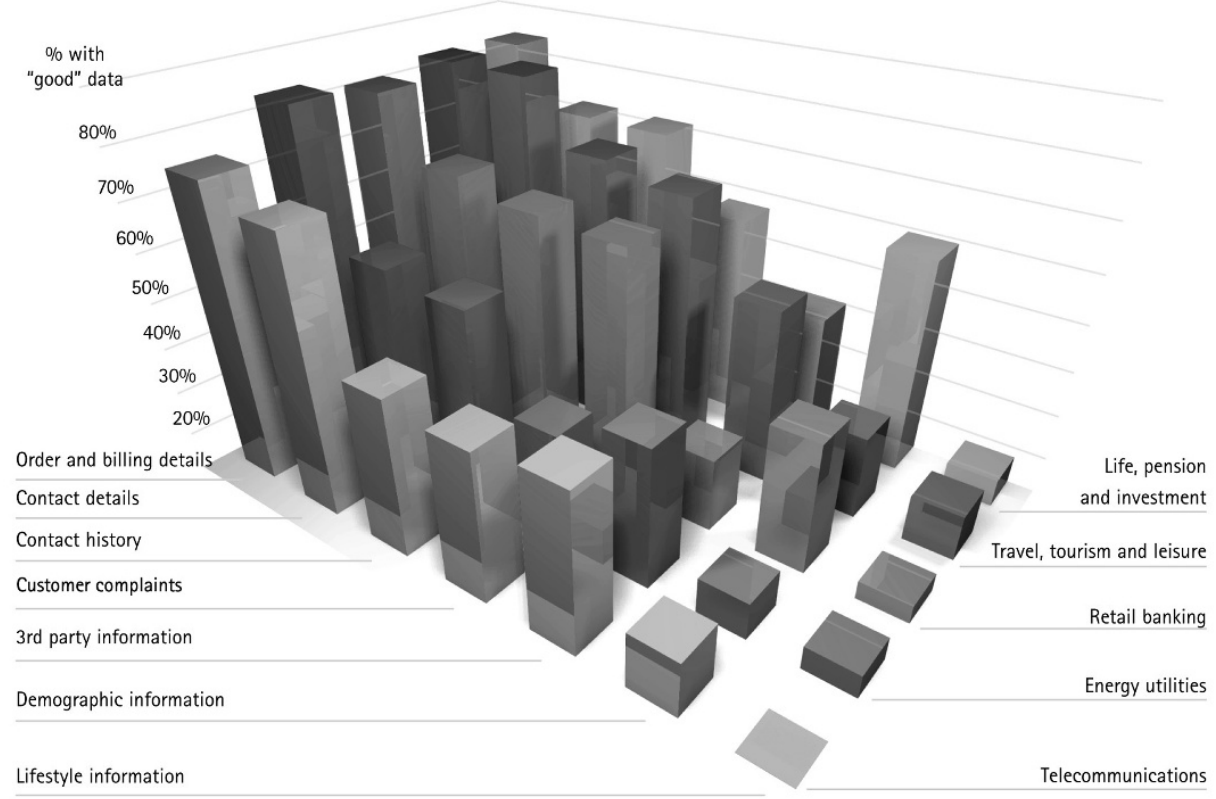

Figure 1 Breakdown of customer data availability and quality by industry sector

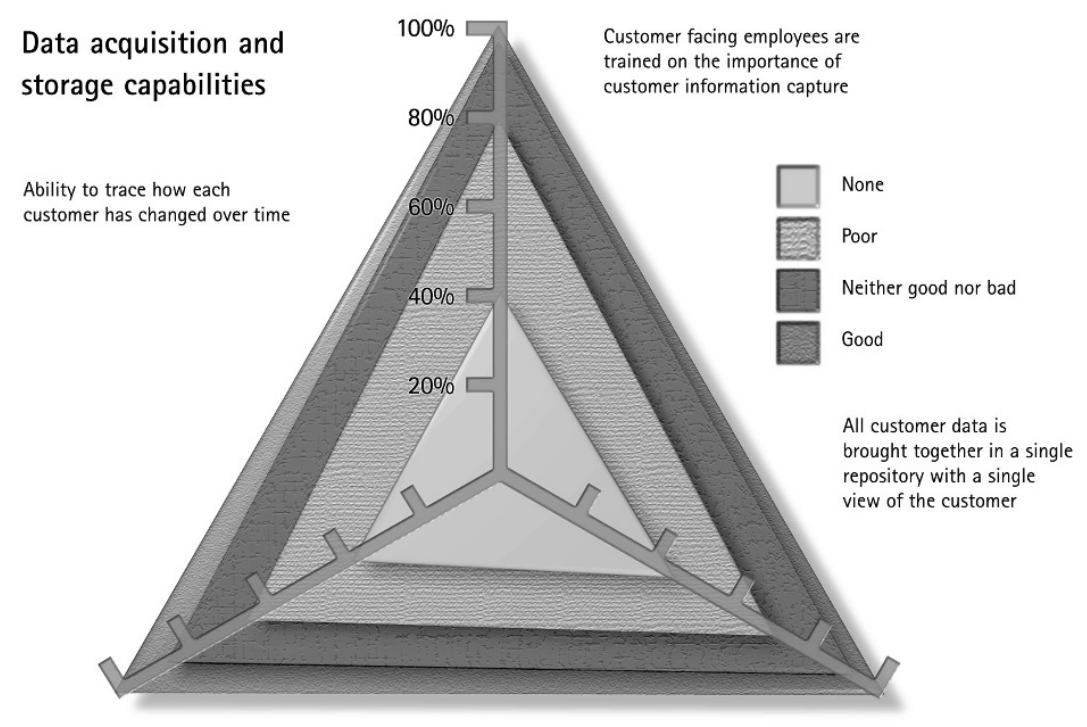

Figure 2 Data acquistion and storage capabilities

more insightful. It is also important to ensure that data are held over time, so that changes and trends of behaviour can be identified. The graph in Figure 2 , from the same research, shows how few companies rank themselves as 'good' at: training, information capture, tracking customer changes of time and bringing data into a single repository. 


\section{Other sources of information}

Activities such as the launch of new services, products, promotions and campaigns are often not supported by specific applications. They do, however, involve significant amounts of effort. If timesheet systems record time spent on specific tasks then measures of effort and duration are possible.

The enabling activities such as training, recruitment, demand forecasting and agent rostering are, by their very nature, supported by information systems, if not specific applications. These provide essential sources of data.

\section{Bringing the information together}

Only a subset of the data and information held in the separate contact centre systems is required to provide a comprehensive set of performance measures. For instance, identifying for each interaction a simple data set will enable detailed measurement, monitoring and analysis of call completion, enquiry resolution, customer acquisition activities, sales activities and service activities. This can consist of the following:

- date

- time

— interaction type

— associated products

- order

- duration on call

- wrap up time

- customer

- agent

— agent's skill profile

— agent's team.

The feeds from each of the operational systems are simple to construct and can in many cases be provided at a frequency of an hour or less. This means that performance can be monitored effectively in near real-time, supporting operational decisions on an hour-by-hour basis. Daily, monthly and quarterly reports can be produced. As the data are not deleted, any new reports can be devised and run across all historic data so that new measures that are defined can be reported not only from the point of inception but also retrospectively.

This simple data set outlined above will enable the value delivered to the customer to be understood from each customer's perspective, in terms of the total number and types of enquiry handled, the number of interactions required to resolve each enquiry, the length of time it took to resolve and the service levels received by each customer.

The business value activities can be measured in terms of the effectiveness of marketing, sales and servicing interactions for each customer, product, campaign and promotion.

The enabling activities can be measured, for example, in terms of the relative performance of the new recruits, the effectiveness of the training programmes, the accuracy of the communication forecasting, the appropriateness of the staff rostered to handle the calls, the effectiveness of the workload management and distribution between teams and agents.

All of the measures above can be reported on over time so allowing trends to be identified. As the data are held at the level of each interaction, variations in performance between teams, agents, products, types of interaction, campaigns, promotions and communications mediums can be explored and monitored. This provides essential information to identify improvements. The information also, by its very nature, enables new value-based remuneration schemes for employees and improved capabilities to track and manage workload hour by hour. 


\section{PUBLISHING PERFORMANCE MEASURES AND INFORMATION}

Measuring performance is of little use unless actions are taken to improve poor performance. Action may not be taken or, worse, may be misdirected for a number of reasons.

Reporting on averages and totals hides variations in performance: understanding the variations in performance for example between agents, teams and locations or between products and channels is fundamental for managers to identify areas of poor performance.

Commentary: notes to explain systems failures, a high incidence of staff sickness, external disasters or the website being down are essential. They provide the background behind the specific fluctuations in performance. Commentary on any corrective actions already taken is also important to prevent unnecessary duplication of effort. Within the publishing process it is therefore vital that individuals who are responsible for each area of performance should be able to add their commentary before the results are published.

Timely communication of measurement: reporting on the service levels achieved and agent workload for a day at the end of the day, when no action can be taken, limits the value of measurement. While monitoring the staff workload and service level on a 15-minute basis can inform decisions to switch calls from heavily-loaded staff to under-utilised staff. This type of decision will improve the contact centre's performance for the day.

Supporting information: measures are often reported without also providing the accompanying information to support the necessary decision making. So, for instance, the staff workload monitoring and service levels report given above could be extended with information in the form of a list of under-utilised agents who have the correct skills profile to handle the call types receiving poor service.

Integrating findings: measures are often reported separately. This leaves the reader to do most of the work in combining and interpreting the information from many different reports. Measures for specific activities need to be combined into single reports that not only show performance but also relate this to budget and forecast performance figures. For example, a single graph combining actual, forecast and budget call volumes, service levels and staffing levels for each half hour of a day is easily assimilated by the reader.

The necessary technologies to support the integration of data from different contact centre systems, to improve the publication and control the dissemination, often exist within the current technology assets of a business. The effort required to put such a system in place is minimal provided that the right approach is taken.

\section{PUTTING IT INTO PRACTICE}

Implementing measurement-based performance improvement is an iterative process, not a single action. Detica's approach to implementing performance improvement is shown in Figures 3 and 4.

The approach shown is typically deployed as a series of incremental phases of action and measurement, enabling the contact centre to continuously improve performance. In this way, the centre is able to maintain its delivery of the intended levels of service at the intended costs to the business.

\section{CONCLUSION}

Existing measures of contact centre activity tend to be focused on metrics that indicate relative levels of overall 
Stage 1: Understand your internal and external customers' needs, expectations and experience

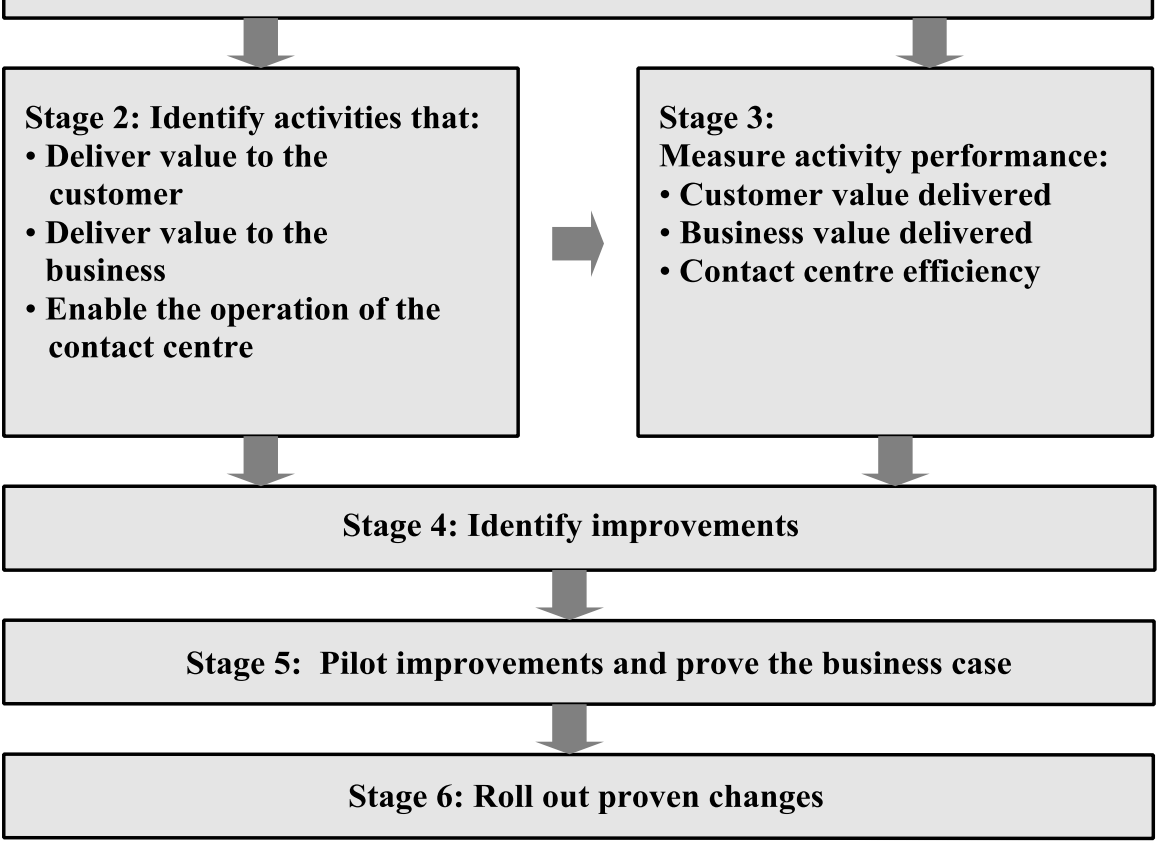

Figure 3 Methodology for contract centre performance

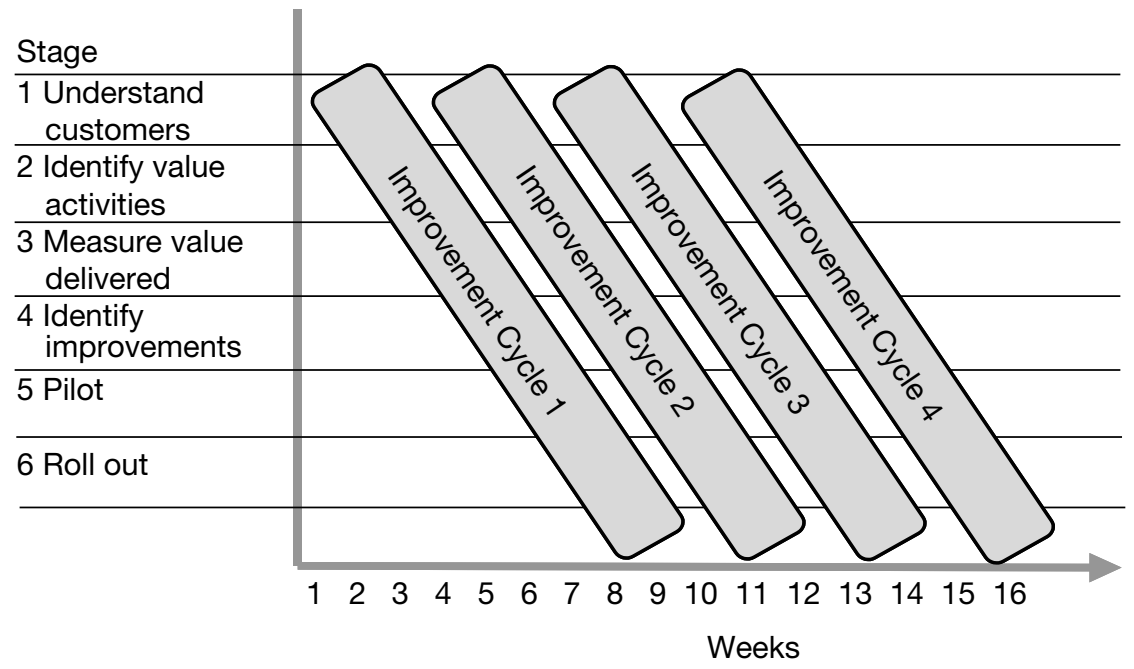

Figure 4 Typical programme timelines

performance. They do not measure the activities at the detailed level and so form a poor basis for performance improvement.

To develop a set of measures of the contact centre performance, in terms of its effectiveness in meeting the business's needs, the operational model of the contact centre should be seen in terms of those activities that deliver value to the customer, value to the business and enable the contact centre to operate efficiently.

Once this is done, the information available to measure these activities can be gathered. This information is 
frequently regarded as being of good quality by companies but few companies rank themselves as being good at training staff to capture information, bringing the data together and forming a single view of a customers' interactions with the business. This is relatively cheap to do and, once completed, provides the basis for ongoing performance measurement and operational analysis.

This information is critical for staff and managers alike as it provides essential visible feedback on what is, on the whole, an invisible mass of interactions. This ensures that management is in control of the operation and can understand the interplay of interdependent activities.

The measurement-based approach to improving performance can be implemented in a matter of weeks. It supports short cycles of improvement and builds a culture of continuous performance improvement.

Viewing the operation both in terms of activities which deliver value then measuring their performance ensures that as improvements are identified they can be piloted and the benefits more easily quantified. The business case for investments in self-service options or supporting systems can therefore be more rigorously challenged. The performance improvement targets that are set to justify these investments can actually be measured and monitored ensuring that operations are being managed to achieve them. This significantly reduces the risk of investment failure.

This approach, which focuses on improved measurement, delivers performance improvements quickly and without significant investment in new technology. It forms the foundation to support other types of initiative as 'what gets measured gets done'.

(C) Detica Limited

\section{References}

1 Datamonitor (2002) 'Call centres in EMEA to 2007', October.

2 Merchants Global Contact Centre Benchmarking Report, 2001.

3 Detica (2002) 'CRM - the customers' indictment', research report, March.

4 Income Data Services (2002) 'Pay and conditions in call centres', research report.

5 Detica (2002) 'Converting customer data into effective decisions - The leaders and followers in the UK market', research report, April. 